\title{
Diagnostic accuracy of evaluation of suspected syncope in the emergency department: usual practice vs. ESC guidelines
}

Veera K. van Wijnen ${ }^{1}$, Reinold O. B. Gans ${ }^{1}$, Wouter Wieling ${ }^{2}$, Jan C. ter Maaten ${ }^{1}$ and Mark P. M. Harms ${ }^{1 *}$ (D)

\begin{abstract}
Background: Syncope is a frequent reason for referral to the emergency department. After excluding a potentially life-threatening condition, the second objective is to find the cause of syncope. The objective of this study was to assess the diagnostic accuracy of the treating physician in usual practice and to compare this to the diagnostic accuracy of a standardised evaluation, consisting of thorough history taking and physical examination by a research physician.

Methods: This prospective cohort study included suspected (pre) syncope patients without an identified serious underlying condition who were assessed in the emergency department. Patients were initially seen by the initial treating physician and the usual evaluation was performed. A research physician, blinded to the findings of the initial treating physician, then performed a standardised evaluation according to the ESC syncope guidelines. Diagnostic accuracy (proportion of correct diagnoses) was determined by expert consensus after long-term followup.

Results: One hundred and one suspected (pre) syncope patients were included (mean age $59 \pm 20$ years). The usual practice of the initial treating physicians did not in most cases follow ESC syncope guidelines, with orthostatic blood pressure measurements made in only $40 \%$ of the patients. Diagnostic accuracy by the initial treating physicians was 65\% (95\% Cl 56-74\%), while standardised evaluation resulted in a diagnostic accuracy of 80\% (95\% Cl 71-87\%; $p=0.009$ ). No life-threatening causes were missed.

Conclusions: Usual practice of the initial treating physician resulted in a diagnostic accuracy of $65 \%$, while standardised practice, with an emphasis on thorough history taking, increased diagnostic accuracy to $80 \%$. Results suggest that the availability of additional resources does not result in a higher diagnostic accuracy than standardised evaluation, and that history taking is the most important diagnostic test in suspected syncope patients. Netherlands Trial Registration: NTR5651. Registered 29 January 2016, https://www.trialregister.nl/trial/5532
\end{abstract}

Keywords: Syncope, Emergency department, Diagnostic accuracy, History taking, Guidelines

\footnotetext{
*Correspondence: m.p.m.harms@umcg.nl

'Department of Internal and Emergency Medicine, University of Groningen, University Medical Center Groningen, PO BOX 30001, 9700 RB Groningen, the Netherlands

Full list of author information is available at the end of the article
}

(c) The Author(s). 2020 Open Access This article is licensed under a Creative Commons Attribution 4.0 International License, which permits use, sharing, adaptation, distribution and reproduction in any medium or format, as long as you give appropriate credit to the original author(s) and the source, provide a link to the Creative Commons licence, and indicate if changes were made. The images or other third party material in this article are included in the article's Creative Commons licence, unless indicated otherwise in a credit line to the material. If material is not included in the article's Creative Commons licence and your intended use is not permitted by statutory regulation or exceeds the permitted use, you will need to obtain permission directly from the copyright holder. To view a copy of this licence, visit http://creativecommons.org/licenses/by/4.0/. The Creative Commons Public Domain Dedication waiver (http://creativecommons.org/publicdomain/zero/1.0/) applies to the data made available in this article, unless otherwise stated in a credit line to the data. 


\section{Background}

Suspected syncope is a frequent presenting symptom in the dynamic setting of the Emergency Department (ED) [1]. The first objective is to recognize a potentially lifethreatening condition in the ED or ED observation unit [2]. After excluding a clear serious condition, the secondary objective is to find the cause of syncope. It is well known that physicians find it challenging to establish the cause of syncope in this large group of patients.

The European Society of Cardiology (ESC) developed the "Syncope Guideline on Diagnosis and Management" to reduce the risk of recurrences and the life-threatening consequences of syncope recurrences [3]. The initial evaluation consists of careful history-taking and physical examination, including an electrocardiogram and orthostatic blood pressure measurement. Despite the introduction of several syncope guidelines [1, 3-5], the current strategies and diagnostic yield of syncope evaluation varies widely between physicians, hospitals and countries [6]. To improve diagnostic yield (i.e., patients receiving a working diagnosis) several studies have applied standardised clinical evaluation, which has resulted in a working diagnosis of between 63 and 95\% [7-9]. However, in daily practice, guideline adherence is not always synonymous with clinical practice [9]. Moreover, most studies did not provide data on the follow-up or prognosis of syncope patients presenting to the ED. Therefore, the diagnostic accuracy (proportion of correct diagnoses) of initial treating physicians in usual practice is unknown [9-11].

We performed a clinical audit to study the diagnostic accuracy of the usual evaluation of suspected syncope in the ED, after excluding a clear serious condition.

\section{Methods}

\section{Setting}

This prospective cohort study was conducted at a tertiary care hospital. The usual practice by the initial treating physician was compared to standardised practice by the research physician. Eligible patients had been referred to the ED from Monday to Friday during regular working hours due to a transient loss of consciousness that, on initial evaluation, was attributed to suspected severe presyncope or syncope. Syncope was defined as a transient loss of consciousness due to transient global cerebral hypoperfusion, characterised by rapid onset, short duration and spontaneous complete recovery [3]. Severe presyncope was defined as the feeling of almost losing consciousness, with similar prodromal symptoms as syncope $[3,12]$.

\section{Population}

Patients were included between December 2015 and February 2017. Patients $\geq 18$ years referred due to suspected syncope and severe presyncope were eligible for inclusion. Exclusion criteria were: a) hemodynamic instability, b) in need of immediate investigations/treatment (i.e., urgent work-up by attending staff, whereby the research process would delay diagnostic/therapeutic care), c) psychologically, physically (due to a serious illness) or cognitively unfit, d) unable to participate in the follow-up study, e) unwilling or unable to give informed consent, f) transient loss of consciousness not fitting the definition of suspected syncope, or g) a life expectancy of less than 1 year. The study was approved by the Medical Ethical Committee and all patients provided informed consent.

\section{Study flow}

\section{Practice as usual by initial treating physicians}

Patients who were referred to the ED and were seen by the Emergency Medicine, Internal Medicine and Cardiology specialists were screened for eligibility to participate in the study. First, patients were assessed by the initial treating physicians, who were usually residents under the supervision of a specialist. The evaluation of a patient with suspected syncope forms part of the resident training program, whereby the ESC guidelines form the standard of care [3]. In addition to the existing resident training program, no specific guidelines were given to the initial treating physicians and therefore the evaluation was a reflection of usual practice (Fig. 1). The working diagnosis given by the initial treating physician was mined from the ED discharge letter, signed by the resident and supervisor (the initial diagnosis included in the letter's conclusion).

\section{Standardised evaluation by the research physician}

After the usual evaluation, the initial treating physician alerted the full-time research physician, who approached the patient to obtain informed consent. The initial treating physicians were explicitly instructed not to reveal their working diagnosis to the research physician. Moreover, the initial treating physicians were unaware of the specific aim of the study. After obtaining informed consent, an extensive history [13] and physical examination, including the analysis of the electrocardiogram and orthostatic BP measurement was performed by the research physician [3]. The research physician, a physician with an in-depth knowledge of orthostatic blood pressure regulation, was trained by a syncope expert to take a standardised in-depth history following the ESC syncope guideline $[3,13,14]$.

\section{Follow-up}

The initial management of (pre) syncope patients in the ED was independent of this study and determined by the initial treating physicians. Nevertheless, the initial treating physicians were aware that all patients received a 


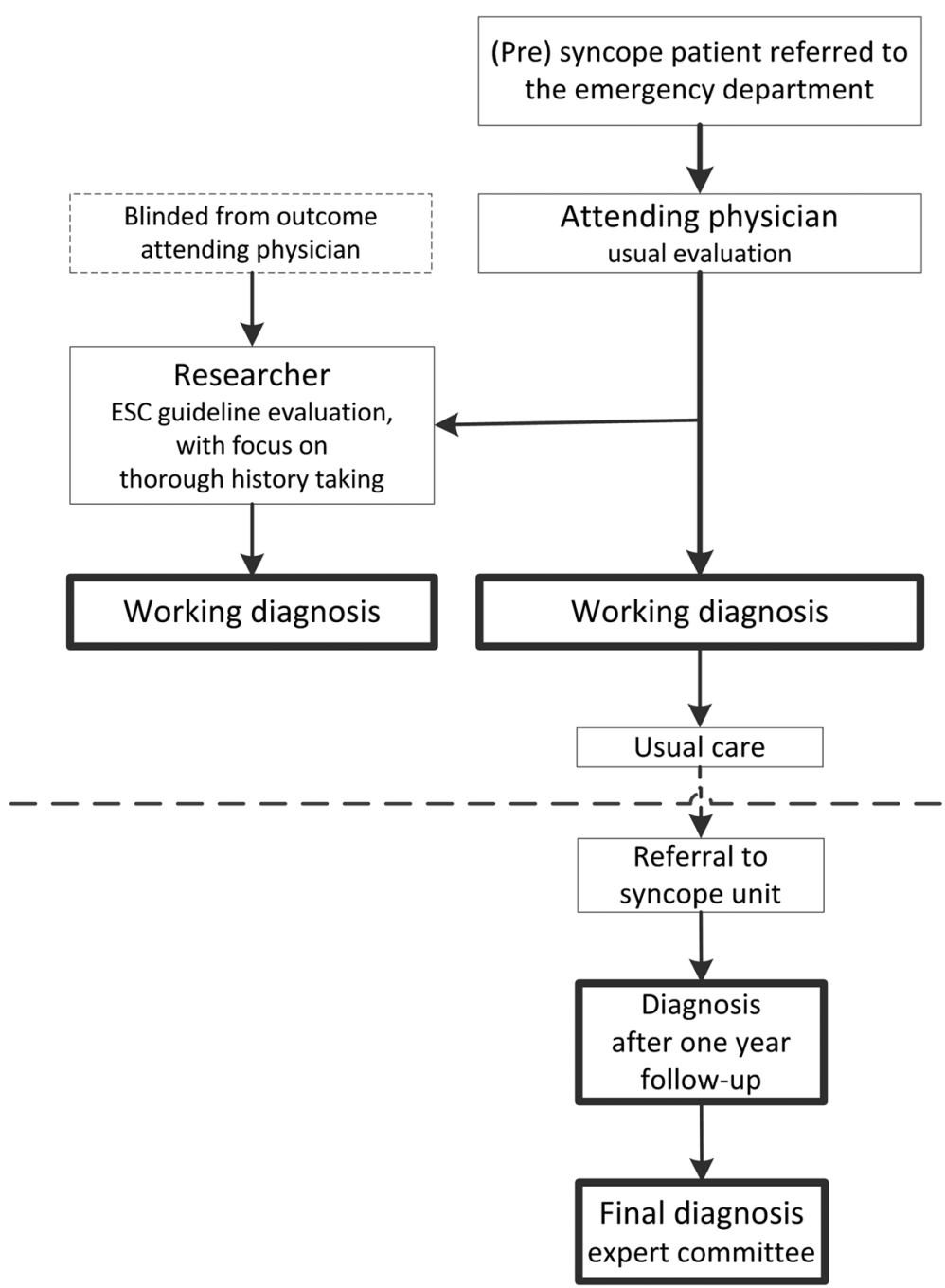

Fig. 1 Study flow diagram

referral to the syncope unit. During the follow-up visit(s) at the syncope unit, additional investigations were performed if this was appropriate (outside the scope of this article). If patients did not present for their appointment, they were contacted by phone or via their General Practitioner at the end of the year to obtain further information regarding recurrences and/or additional investigations. The diagnosis was determined at the syncope unit after one-year follow-up. We also classified the clinical certainty of the diagnosis that was made, according to Van Dijk et al. [7], into a certain (100\%), highly likely (80-100\%), likely $(60-80 \%)$ or uncertain $(<60 \%)$ diagnosis. A certain diagnosis met the criteria as described by van Dijk et al. [7].

\section{Reference standard}

To determine diagnostic accuracy (proportion of diagnoses in the correct diagnostic category), a reference standard was required. As no independent reference standard for syncope exists [13], all information obtained during long-term follow-up was used to test the reliability of the diagnosis through assessment by an independent expert committee [7, 14]. To obtain the final diagnosis, the following procedure was used: Patients who received the same diagnosis by the initial treating physician, the research physician and after one-year of follow-up (defined as certain or highly likely), were classified as having received the correct diagnosis. All other cases were reviewed by the expert committee.

\section{Expert committee}

The expert committee consisted of three independent syncope specialists (a cardiologist, neurologist, and an internist) with many years of experience in the field [1517]. The experts were not members of the study group. The expert committee reviewed all available information 
summarised per patient and decided upon a final diagnosis. When all experts agreed on a diagnosis or two members agreed on a diagnosis and the third member made no diagnosis, this diagnosis was taken as the final diagnosis. Finally, a face-to-face consensus meeting was held to discuss the cases in which no agreement had been reached. If an agreement was then reached, this was designated the final diagnosis [7].

\section{Outcomes}

\section{Diagnostic accuracy}

Diagnostic accuracy was defined as the proportion of correct diagnosis after the initial evaluation in the correct diagnostic category (reflex syncope, cardiac syncope, initial orthostatic hypotension, orthostatic hypotension, psychogenic pseudosyncope, or non-syncope (e.g., hyperventilation, hypoglycemia, epilepsy) [7].

\section{Adverse events}

Adverse events were defined as death, life-threatening arrhythmia, acute myocardial infarction, severe structural heart disease, aortic dissection, pulmonary embolus, cerebrovascular accident, subarachnoid hemorrhage, significant hemorrhage, another severe condition or procedural interventions, which occurred within 30 days after referral to the ED [18].

\section{Statistical analysis}

IBM SPSS Statistics 23 was used for analyses. Continuous data were expressed as mean (SD) or median (interquartile range) where appropriate, and categorical data as percentages. Between-group differences in continuous data were analysed using Student's t-test or nonparametric tests where appropriate. Diagnostic accuracy was expressed in proportions and the method by Wilson was used to calculate $95 \%$ confidence intervals. Statistical significance was set at $p<0.05$.

\section{Results}

\section{Patient characteristics}

Two hundred and 18 suspected syncope patients were screened for inclusion. Of these patients, 117 (53.7\%) were ineligible to participate due to refusal to participate $(n=38)$ or because of the presence of an exclusion criterion $(n=79)$. The reasons for exclusion were hemodynamic instability $(n=5)$, in need of immediate investigations/treatment $(n=17)$, psychologically, physically or cognitively unfit $(n=31)$, unable to participate in the follow-up study $(n=8)$, transient loss of consciousness not fitting the definition of suspected syncope $(n=$ $11)$, a life expectancy of less than 1 year $(n=3)$, or the presence of a language barrier $(n=4)$. The differences observed between the included and excluded patient groups were found in the suspected diagnosis categories, admission rate and all-cause mortality (Table 1 ).

The included 101 patients had a mean age of $59 \pm 20$ years and $66(65.3 \%)$ were male. Twenty-nine (28.7\%) patients were referred due to severe presyncope and 72 (71.3\%) patients due to syncope. Fifty-four (53.5\%) patients had a history of cardiovascular disease and 63 (62.4\%) a history of syncope (Table 2).

\section{Usual practice by the initial treating physicians}

The initial evaluation by the initial treating physicians consisted of a history and physical examination, including an electrocardiogram in $100 \%$ of the patients (Table 2). Orthostatic blood pressure measurement was performed in 40/101 (39.6\%) patients. Furthermore, laboratory tests were performed in 97 (96.0\%) patients, chest $\mathrm{x}$-ray in $18(17.8 \%)$ and computed tomography (head or chest) in 14 (13.8\%). Another specialty was consulted for 33/101 patients. No adverse events occurred within 30 days.

\section{Diagnostic accuracy of the diagnosis at presentation Expert committee}

Forty-two (41.6\%) patients were assessed by the expert committee. In 19/42 patients, the experts agreed during the paper round. The other 23/42 patients were discussed during a face-to-face meeting. Finally, seven patients did not receive a diagnosis.

\section{Diagnostic accuracy of the initial treating physicians and research physician}

The diagnostic accuracy of the initial treating physicians was $65 \%$ (95\% CI: $56-74 \%$ ) and of the research physician 80\% (95\% CI: 71-87\%; $p=0.009$; Table 3, Fig. 2). The diagnosis of the initial treating physicians corresponded to the diagnosis of the research physician in 59/66 cases (89.4\%).

\section{Diagnostic accuracy of the diagnostic categories}

A diagnosis of reflex syncope, combining vasovagal and situational syncope, was the most common diagnosis (Table 3, Fig. 2). Diagnostic accuracy for the diagnosis of reflex syncope was 78\% (95\% CI: $67-86 \%$ ) for the initial treating physicians and $85 \%$ (95\% CI: $75-92 \%)$ for the research physician. No cardiac syncope was missed. However, eight patients received a working diagnosis of cardiac syncope from the initial treating physicians, while the expert committee categorised these patients differently. Initial orthostatic hypotension was the cause of (pre) syncope for four patients; however, no diagnosis of initial orthostatic hypotension was made by the initial treating physicians. Orthostatic hypotension was the second most common cause of syncope (14\%); the diagnostic accuracy of the initial treating physician and the 
Table 1 Group characteristics of suspected (pre) syncope patients in the Emergency Department

\begin{tabular}{|c|c|c|c|}
\hline & Included $N=101$ & Excluded $N=117$ & $\boldsymbol{P}$ value \\
\hline \multicolumn{4}{|l|}{ Demographics } \\
\hline Male, $n(\%)$ & $66(65.3)$ & $62(53.0)$ & 0.065 \\
\hline Age, mean $\pm S D$ & $59 \pm 20$ & $61 \pm 21$ & 0.280 \\
\hline Specialists in the ED, $n(\%)$ & & & 0.177 \\
\hline •Emergency Medicine & $62(61.4)$ & $58(49.6)$ & \\
\hline - Internal Medicine & $14(13.9)$ & $27(23.1)$ & \\
\hline -Cardiology & $25(24.8)$ & $32(27.4)$ & \\
\hline Diagnosis by initial treating physician, $n(\%)$ & & & $<0.001^{*}$ \\
\hline •Vasovagal reflex syncope & $54(53.5)$ & $36(30.8)$ & \\
\hline -Situational reflex syncope & $3(3.0)$ & $2(1.7)$ & \\
\hline -Carotid sinus hypersensitivity & - & - & \\
\hline -Cardiac syncope & $10(9.9)$ & $27(23.1)$ & \\
\hline -Initial orthostatic hypotension & - & - & \\
\hline -Orthostatic hypotension & $14(13.9)$ & $14(12.0)$ & \\
\hline -Psychogenic pseudosyncope & - & - & \\
\hline -Other cause, non-syncope & $7(6.9)$ & $10(8.5)$ & \\
\hline •Unknown & $13(12.9)$ & $28(23.9)$ & \\
\hline Admission, $n(\%)$ & $16(15.8)$ & $53(45.3)$ & $<0.001 *$ \\
\hline \multicolumn{4}{|l|}{ All-cause mortality, $n(\%)$} \\
\hline -30 days & - & $3(2.6)$ & - \\
\hline$\cdot 1$ year & $5(5.0)$ & $18(15.4)$ & $0.005^{*}$ \\
\hline
\end{tabular}

ED Emergency Department. *Statistically significant at $p<0.05$.

research physician were 57\% (95\% CI: $33-79 \%)$ and $100 \%$ (95\% CI 78-100\%), respectively. However, the research physician misclassified six patients with presumed orthostatic hypotension. Finally, two patients were classified by the experts as having psychogenic pseudosyncope. The initial treating physicians did not classify any patients with this diagnosis.

\section{Diagnostic accuracy after one-year follow-up}

In addition to the diagnostic accuracy of the initial evaluation in the ED, the accuracy of the diagnosis made after 1 year of follow-up was also assessed. Diagnostic accuracy after one-year follow-up was 89\% (95\% CI: $81-94 \%)(p<$ 0.001 and $p=0.012$ comparing the initial treating physicians and research physician in the ED, respectively). Of the patients who received a certain diagnosis $(n=34)$, one patient was judged differently by the expert committee. In the group with highly likely diagnoses $(n=48)$, one diagnosis was different according to the expert committee. In the category of likely diagnosis, eight patients received another diagnosis by the expert committee.

\section{Discussion}

In this clinical audit, the diagnostic accuracy of the usual evaluation of suspected syncope in the ED was assessed, after excluding a clear serious condition. The usual method of syncope evaluation by initial treating physicians in the ED resulted in a diagnostic accuracy of $65 \%$. A diagnostic accuracy of $80 \%$ was achieved after a standardised evaluation by the research physician, with the emphasis on thorough history-taking. The availability of additional resources (tests and/or consultations) did not result in a higher accuracy than the standardised assessments.

\section{Diagnostic accuracy of the usual method of practice by initial treating physicians}

Although the ESC syncope guideline is the standard taught in residents' training programs, the usual method of evaluation by the initial treating physicians did not, in most cases, proceed according to the ESC guidelines [3]. Orthostatic blood pressure measurement was performed in only $40 \%$ of patients, and in addition many additional tests (96\%) and consultations (33\%) were performed. This is the first study to determine the diagnostic accuracy of the usual practice of initial treating physicians using expert consensus as the reference standard after long-term follow-up. Previous studies have focused on (increasing) diagnostic yield $[8,9,19]$; whether the working diagnosis was correct or incorrect was usually 
Table 2 Additional patient characteristics of included (pre)syncope patients

\begin{tabular}{|c|c|}
\hline Arrival by ambulance, $\mathrm{n}(\%)$ & $71(71.0)$ \\
\hline Cardiovascular history, n (\%) & $54(53.5)$ \\
\hline - Hypertension & $40(39.6)$ \\
\hline - Myocardial infarction & $14(13.9)$ \\
\hline - Heart failure & $4(4.0)$ \\
\hline - Rhythm disorders (AF, VT) & $15(14.9)$ \\
\hline - Pacemaker/ICD & $5(5.0)$ \\
\hline - Peripheral vascular disease & $9(8.9)$ \\
\hline - Thrombosis & $8(7.9)$ \\
\hline Parkinson's disease & $3(3.0)$ \\
\hline Diabetes mellitus & $12(11.9)$ \\
\hline History of syncope & $63(62.4)$ \\
\hline Antihypertensive medication, $\mathrm{n}(\%)$ & $46(45.5)$ \\
\hline • B-blocker & $25(24.8)$ \\
\hline - ACE inhibitor or angiotensin II blocker & $31(30.7)$ \\
\hline - Calcium antagonist & $9(8.9)$ \\
\hline - Diuretics & $21(20.8)$ \\
\hline$\cdot \geq 2$ antihypertensive drugs & $29(28.7)$ \\
\hline Antidepressants & $8(7.9)$ \\
\hline Polypharmacy ( $\geq 5$ ) & $40(39.6)$ \\
\hline ECG performed & $\begin{array}{l}101 \\
(100.0)\end{array}$ \\
\hline $\begin{array}{l}\text { Orthostatic BP test performed by initial treating } \\
\text { physicians }\end{array}$ & $40(39.6)$ \\
\hline \multicolumn{2}{|l|}{ Additional tests performed in the ED, $n(\%)$} \\
\hline - Laboratory tests & $97(96.0)$ \\
\hline - Chest x-ray & $18(17.8)$ \\
\hline - Computed tomography (head or chest) & $14(13.8)$ \\
\hline Consultation of another specialist in the ED, $\mathrm{n}(\%)$ & $33(32.7)$ \\
\hline - One specialist & $27(26.7)$ \\
\hline - Two specialists & $6(5.9)$ \\
\hline \multicolumn{2}{|l|}{ Department of admission, $\mathrm{n}(\%)$} \\
\hline • Cardiology & $5(31.2)$ \\
\hline - Internal Medicine & $10(62.5)$ \\
\hline • Neurology & $1(6.3)$ \\
\hline Median number of days hospitalised (range) & $\begin{array}{l}3.13(1- \\
13)\end{array}$ \\
\hline
\end{tabular}

$A F$ atrial fibrillation, $B P$ blood pressure, $E D$ Emergency Department, $I C D$ implantable cardioverter-defibrillator, VT ventricular tachycardia

neglected [7]. Van Dijk and colleagues were the first to assess the diagnostic accuracy of the initial treating physicians in a tertiary ED, applying a standardised-care pathway in the evaluation of 112 suspected syncope patients [7]. They found that the initial evaluation was performed according to ESC guidelines, resulted in an overall diagnostic accuracy of $70 \%$ [7]. This percentage is slightly higher than the non-standardised evaluation observed in our ED. However, the populations of these two studies cannot directly be compared, as the mean age of patients in the study by Van Dijk was considerably lower ( $45 \pm 18$ vs. $59 \pm 20$ years) and subjects were less likely to have cardiovascular comorbidities. However, the results of these two studies suggest that standardised and non-standardised care (with use of additional resources) by treating physicians in the ED results in a diagnostic accuracy between 65 and $70 \%$.

\section{Diagnostic accuracy after standardised evaluation}

The findings of this study suggest that a standardised evaluation, with the emphasis on thorough historytaking, will further improve diagnostic accuracy in the evaluation of syncope patients in the ED. The importance of history taking in syncope patients has previously been addressed; however, these studies have usually referred to history taking by syncope experts in syncope units $[13,14,20]$. To improve history taking, physicians need to be able to link clinical clues from the medical history to physiology [21]. The key to successful syncope history-taking is to allow sufficient time to carefully listen to the patient with undivided attention [13]. Moreover, it is important to realise that reflex syncope and orthostatic hypotension are the most common causes of syncope, and therefore physicians caring for patients with suspected syncope should have an understanding of circulatory physiology and pathophysiology [22]. Following on from this, orthostatic vital signs are indicated in all suspected syncope patients. We argue that to obtain the diagnosis of syncope, a thorough history and physical examination by a capable physician is often all that is necessary to reach a diagnosis and begin therapy [20].

\section{Clinical relevance of improved diagnostic accuracy}

An accurate diagnosis is important in order to explain the mechanism of the episode to the worried patient and to determine the correct management and follow-up [14]. It can be argued that an evaluation within the dynamic setting of the ED is focused on risk stratification, and it is true that life-threatening causes must first be excluded. However, patients need more reassurance than "it's not epilepsy or your heart" [15]. Furthermore, distinguishing between the diagnostic categories is important due to varying associated risks. Cardiac syncope carries the highest risk, and admission and treatment of the underlying cause here is crucial $[3,23]$. In addition, orthostatic hypotension is also related to an increased risk of serious outcomes within the first 30 days after ED evaluation, and is generally associated with an increased risk of cardiovascular morbidity and mortality [24, 25]. Patients with vasovagal reflex syncope are not at an increased risk of death; however, unexplained syncope and 
Table 3 Diagnostic accuracy of initial treating physicians and research physician

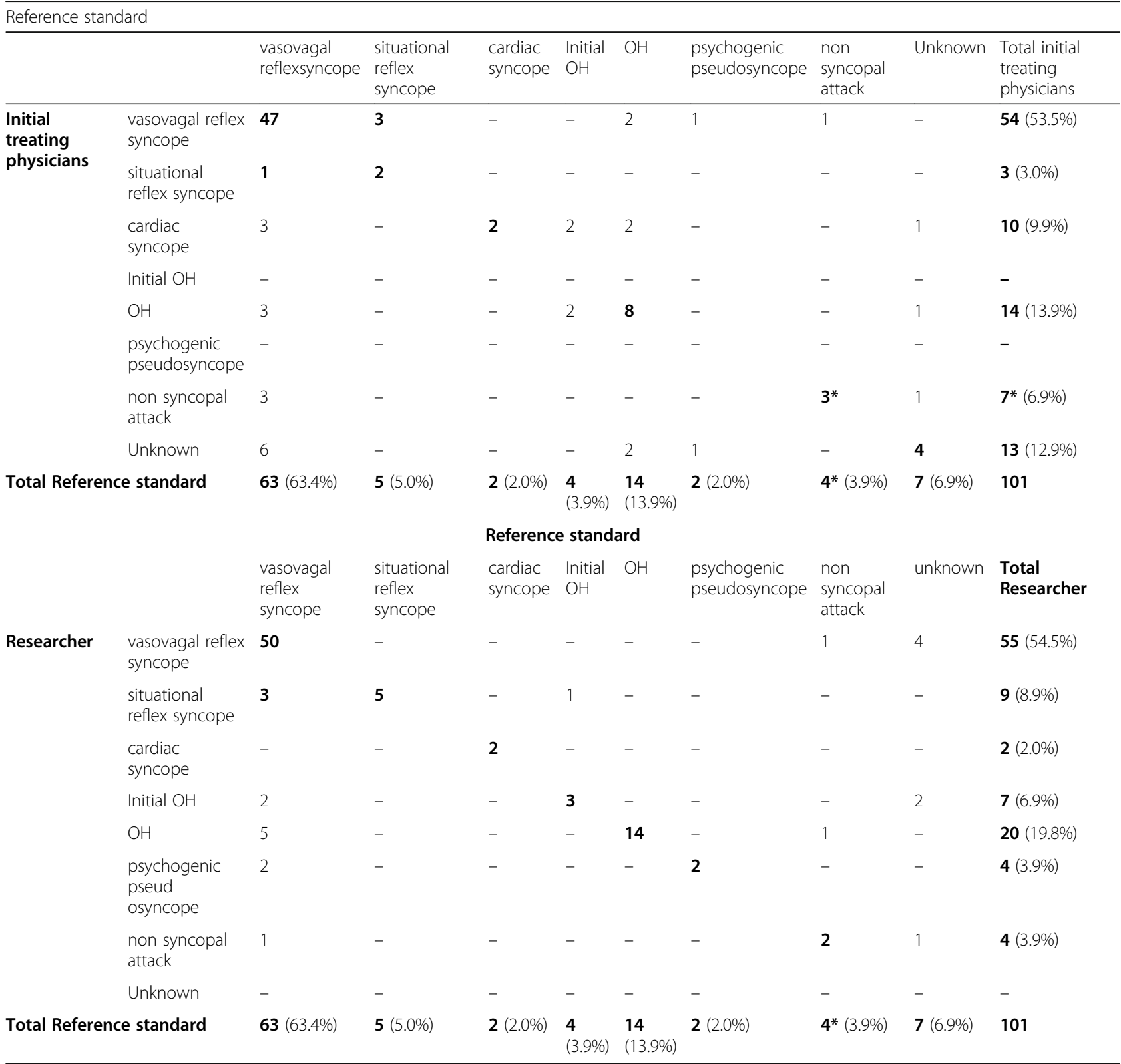

Diagnostic accuracy is defined as the proportion of patients with a diagnosis after initial evaluation in the correct diagnostic category (using expert consensus after long-term follow-up). In both tables, the reference standard represents that correct diagnostic category. The upper table compares the working diagnosis made by the initial treating physicians to the reference standard. The lower table compares the working diagnosis made by the researcher with the reference standard. *Indicates one patient diagnosed with epilepsy. $\mathrm{OH}=$ orthostatic hypotension

recurrent reflex syncope are associated with excessive diagnostic testing and decreased quality of life [24, 26].

In addition, initial orthostatic hypotension and psychogenic pseudosyncope are recognised causes of suspected syncope in the ED, but are under recognised by most attending physicians. In young subjects with initial orthostatic hypotension, simple and effective advice can be given to prevent new episodes (counter pressure manoeuvers) [27]. In elderly subjects, initial orthostatic hypotension with a delayed recovery of BP has been recognised as a cause of (pre) syncope shortly after standing up [28]. Finally, psychogenic pseudosyncope is important to diagnose as patients then require specialty consultation. A combination of specific features from the history usually reveals the diagnosis to the attending physician who is alert to it.

\section{Final diagnosis after one year of follow-up}

The reference standard used in this study, namely expert consensus after one-year of follow-up, is the best reference standard available, but is imperfect [3, 14]. Longterm follow-up has the advantage of providing more 


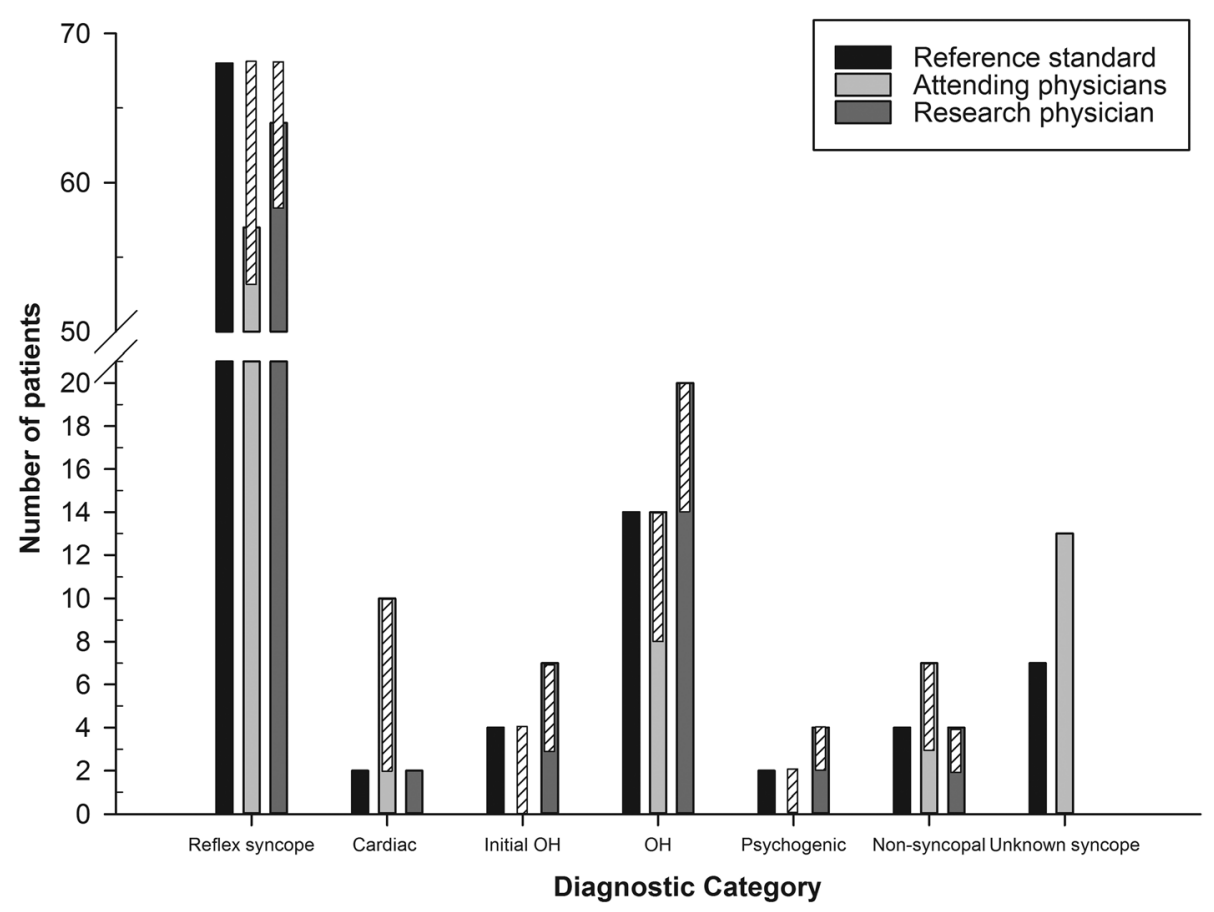

Fig. 2 Diagnostic accuracy of the initial treating physicians and research physician against the reference standard. The bar with slashes represents the total misdiagnoses by the initial treating physicians and research physician. Vasovagal and situational syncope were grouped together under reflex syncope

information regarding additional tests, recurrences and morbidity, but simultaneously it can make assessment of the 'first' episode harder for the expert committee. Moreover, the expert committee may be less likely to categorise borderline cases as cardiac, as they do not have the responsibility of patient care.

In previous studies without expert consensus, very strict criteria were used to define a 'certain' diagnosis, leading to lower number of patients with a diagnosis [4]. Therefore, Van Dijk et al. advocated that accepting more uncertainty would increase diagnostic yield and diagnostic accuracy, and extensive testing can be avoided [7].

The results of this study characterise the challenges that arise in diagnosing patients with syncope and determining diagnostic accuracy. The results imply that physicians dealing with suspected (pre) syncope patients on a regular basis should gather sufficient knowledge of historical clues and physical findings to recognise major causes of transient loss of consciousness (including mimics) and syndromes of orthostatic intolerance [22, 29]. There should be an emphasis on thorough history taking when discussing ways to improve syncope practice and knowledge.

\section{Limitations}

Several limitations affected generalisability and replicability. The study population was a selected population from the ED of a tertiary teaching hospital and patients with an identified serious condition were excluded. This is the likely explanation that there were no adverse events within 30 days of follow-up. However, the age and cardiovascular comorbidity of this population was comparable to a large Italian multi-center study of syncope patients [9]. Furthermore, as this study compared the initial evaluation of many treating physicians, it is a true representation of daily practice in an ED in the Netherlands. However, this makes replication of the study difficult. The diagnostic accuracy of the diagnosis made after 1 year of follow-up at the syncope unit was high, but not $100 \%$. This indicates that, despite follow-up at a syncope unit, a group of patients will remain difficult to classify. Lastly it is important to address the possibility of bias, the so-called Hawthorne effect. Even though the treating physicians were not aware of the study aim, it is possible that they modified their assessment because of their awareness of being observed, and therefore performing better than generally.

\section{Conclusion}

The usual evaluation of suspected syncope in the ED by the initial treating physician resulted in a diagnostic accuracy of $65 \%$, while standardised assessment according to the ESC guideline with an emphasis on thorough history-taking increased diagnostic accuracy to $80 \%$. These results suggest that the usual practice has a lower diagnostic accuracy, and that applying the ESC 
guidelines could result in less testing being required to obtain the correct diagnosis.

\section{Abbreviations}

ED: Emergency Department; ESC: European Society of Cardiology: OH: Orthostatic Hypotension; WS: Vasovagal Syncope

\section{Acknowledgements}

We are very grateful for the time and expertise of Dr. R.D. Thijs (neurologist), Dr. C.T.P Krediet (internist) and Dr. F.J. de Lange (cardiologist) for participating as the syncope expert committee in this study.

\section{Availability of data and material}

The datasets used and/or analysed during the current study available from the corresponding author on reasonable request.

\section{Authors' contributions}

VkvW designed and conducted the study, analyzed the results and wrote the manuscript. RobG provided important feedback on the study design, and cowrote the manuscript. WW was involved in the design of the study, analysis of the results and important feedback on the manuscript. JCtM was involved in the design of the study, co-conducting the study and writing of the manuscript. MpmH designed and conducted the study, analyzed the results and wrote the manuscript

\section{Funding}

There was no funding for this study.

\section{Ethics approval and consent to participate}

The study was approved by the 'Medisch Ethische Toetsingscommissie UMC Groningen' and all patients provided written informed consent.

\section{Consent for publication}

Not Applicable.

\section{Competing interests}

The authors declare that they have no conflicts of interest.

\section{Author details}

'Department of Internal and Emergency Medicine, University of Groningen, University Medical Center Groningen, PO BOX 30001, 9700 RB Groningen, the Netherlands. ${ }^{2}$ Department of Internal Medicine, University of Amsterdam, Academic Medical Center, Amsterdam, the Netherlands.

Received: 23 January 2020 Accepted: 3 June 2020

Published online: 03 August 2020

\section{References}

1. Writing Committee Members, Shen WK, Sheldon RS, et al. 2017 ACC/AHA/ HRS guideline for the evaluation and management of patients with syncope: a report of the American College of Cardiology/American Heart Association task force on clinical practice guidelines and the Heart Rhythm Society, Heart Rhythm 2017;14:e155-e217.

2. Mechanic OJ, Pascheles CY, Lopez GJ, Winans AM, Shapiro NI, Tibbles C, et al. Using the Boston Syncope observation management pathway to reduce hospital admission and adverse outcomes. West J Emerg Med. 2019. 20(2):250-5

3. Brignole M, Moya A, de Lange FJ, et al. 2018 ESC guidelines for the diagnosis and management of syncope. Eur Heart J. 2018;39:1883-948,

4. Linzer M, Yang EH, Estes NA 3rd, et al. Diagnosing syncope. Part 1: value of history, physical examination, and electrocardiography. Clinical efficacy assessment project of the American College of Physicians. Ann Intern Med. 1997;126:989-96

5. Huff JS, Decker WW, Quinn JV, et al. Clinical policy: critical issues in the evaluation and management of adult patients presenting to the emergency department with syncope. Ann Emerg Med. 2007;49:431-44.

6. Disertori M, Brignole M, Menozzi $C$, et al. Management of patients with syncope referred urgently to general hospitals. Europace. 2003;5:283-91.

7. van Dijk N, Boer KR, Colman N, et al. High diagnostic yield and accuracy of history, physical examination, and ECG in patients with transient loss of consciousness in FAST: the fainting assessment study. J Cardiovasc Electrophysiol. 2008:19:48-55.

8. Sarasin FP, Louis-Simonet M, Carballo D, et al. Prospective evaluation of patients with syncope: a population-based study. Am J Med. 2001;111: $177-84$

9. Brignole M, Ungar A, Bartoletti A, et al. Standardized-care pathway vs. usual management of syncope patients presenting as emergencies at general hospitals. Europace. 2006;8:644-50.

10. Olde Nordkamp LR, van Dijk N, Ganzeboom KS, et al. Syncope prevalence in the ED compared to general practice and population: a strong selection process. Am J Emerg Med. 2009:27:271-9.

11. Blanc JJ, L'Her C, Touiza A, et al. Prospective evaluation and outcome of patients admitted for syncope over a 1 year period. Eur Heart J. 2002;23. $815-20$

12. Grossman SA, Babineau M, Burke L, et al. Do outcomes of near syncope parallel syncope? Am J Emerg Med. 2012;30:203-6.

13. Wieling W, van Dijk N, de Lange FJ, et al. History taking as a diagnostic test in patients with syncope: developing expertise in syncope. Eur Heart J. 2015;36:277-80

14. Sutton R, van Dijk N, Wieling W. Clinical history in management of suspected syncope: a powerful diagnostic tool. Cardiol J. 2014;21:651-7.

15. Wieling W, Thijs RD, Linzer M, et al. Great expectations: what patients with unexplained syncope desire. J Intern Med. 2016;279:259-64.

16. van Dijk JG, Thijs RD, Benditt DG, et al. A guide to disorders causing transient loss of consciousness: focus on syncope. Nat Rev Neurol. 2009;5: $438-48$

17. Krediet $C T$, Jardine $D L$, Wieling W. Dissection of carotid sinus hypersensitivity: the timing of vagal and vasodepressor effects and the effect of body position. Clin Sci (Lond). 2011;121:389-96.

18. Benditt DG. Syncope risk assessment in the emergency department and clinic. Prog Cardiovasc Dis. 2013:55:376-81.

19. Shin TG, Kim JS, Song HG, et al. Standardized approaches to syncope evaluation for reducing hospital admissions and costs in overcrowded emergency departments, Yonsei. Med J. 2013;54:1110-8.

20. Cannom DS. History of syncope in the cardiac literature. Prog Cardiovasc Dis. 2013;55:334-8

21. Wieling W, Thiis RD, van Dijk N, et al. Symptoms and signs of syncope: a review of the link between physiology and clinical clues. Brain. 2009;132: $2630-42$.

22. de Jong JSY, de Lange FJ, van Dijk N, et al. Syncopedia: training a new generation of syncope specialists. Clin Auton Res. 2018:28:173-6.

23. Soteriades ES, Evans JC, Larson MG, et al. Incidence and prognosis of syncope. N Engl J Med. 2002;347:878-85.

24. Toarta C, Mukarram M, Arcot K, et al. Syncope prognosis based on emergency department diagnosis: a prospective cohort study. Acad Emerg Med. 2018;25:388-96.

25. Ricci F, De Caterina R, Fedorowski A. Orthostatic hypotension: epidemiology, prognosis, and treatment J Am Coll Cardiol. 2015;66:848-60.

26. Romme JJ, Reitsma JB, Go-Schon IK, et al. Prospective evaluation of nonpharmacological treatment in vasovagal syncope. Europace. 2010;12:567-73.

27. van Wijnen VK, Harms MP, Go-Schon IK, et al. Initial orthostatic hypotension in teenagers and young adults. Clin Auton Res. 2016;26:441-9.

28. van Wijnen VK, Finucane C, Harms MPM, et al. Noninvasive beat-to-beat finger arterial pressure monitoring during orthostasis: a comprehensive review of normal and abnormal responses at different ages. J Intern Med. 2017;282:468-83.

29. Kenny RA, Brignole M, Dan GA, et al. Syncope unit: rationale and requirement--the European heart rhythm association position statement endorsed by the Heart Rhythm Society. Europace. 2015;17:1325-40.

\section{Publisher's Note}

Springer Nature remains neutral with regard to jurisdictional claims in published maps and institutional affiliations. 